\title{
The Arnold Berliner Award 2014
}

\author{
Sven Thatje
}

Received: 28 April 2014 /Revised: 28 April 2014 / Accepted: 28 April 2014 / Published online: 7 May 2014

(C) Springer-Verlag Berlin Heidelberg 2014

The Arnold Berliner Award (Thatje 2012) was established as part of the 100-year anniversary of Naturwissenschaften and was first awarded in 2013 (Fig. 1, Thatje 2013). With this editorial, it is my great pleasure to announce this year's recipient of the award, Florian Karolyi from the University of Vienna.

Florian Karolyi (Fig. 2) was nominated for his interdisciplinary work on the nectar feeding of flies with extremely elongated suction organs (Karolyi et al. 2012). A well-developed suction pump in the head represents an important adaptation for nectarfeeding insects, such as Hymenoptera, Lepidoptera, and Diptera. This pumping organ creates a pressure gradient along the proboscis, the tubular feeding and sucking organ of insects, which is responsible for nectar uptake. Convergent evolution of suction organs and mouthparts, to exclusively access long-tubed flowers, has long been discussed in the literature, but explanations for the ecological or physiological advantages or disadvantages of such a specialist feeding mode largely remained theoretical. The extremely elongated proboscis of the genus Prosoeca (Nemestrinidae) evolved as an adaptation to feeding from such deep flowers and shows considerable length variation. According to the functional constraint hypothesis, flies with a disproportionally long proboscis should have an increased flower handling time and therefore increased time associated with feeding in comparison with individuals with a shorter proboscis. To test this hypothesis, Karolyi and his team used field video analyses of flowervisiting behavior in flies, detailed examinations of suction pump morphology, and correlations of proboscis length with body length and suction pump dimensions. Using a biomechanical framework described for nectar feeding in relation to

S. Thatje $(\bowtie)$

Ocean and Earth Science, University of Southampton, European

Way, Southampton SO14 3ZH, UK

e-mail: svth@noc.soton.ac.uk proboscis length and suction pump musculature, they describe and contrast the system in long-proboscid flies using a variety of cutting edge methodologies. Flies with longer proboscises spent significantly more time drinking from flowers. In addition, proboscis length and body length showed a positive allometric relationship. Furthermore, there is a relationship between proboscis length and suction pump muscle volume and a combination of two pumping organs, indicating that suction efficiency in long-proboscis flies is increased. Surprisingly, time to insert the proboscis into the flower did not vary among short- and long-proboscis flies. Overall, longproboscis flies were shown to be able to take up more nectar in a single flower visit, providing them with a potential energetic advantage.

Nemestrinid flies are high-speed, continuous foragers and adaptation to this lifestyle demands an efficient foraging strategy. The study provides detailed insight into the energetic and

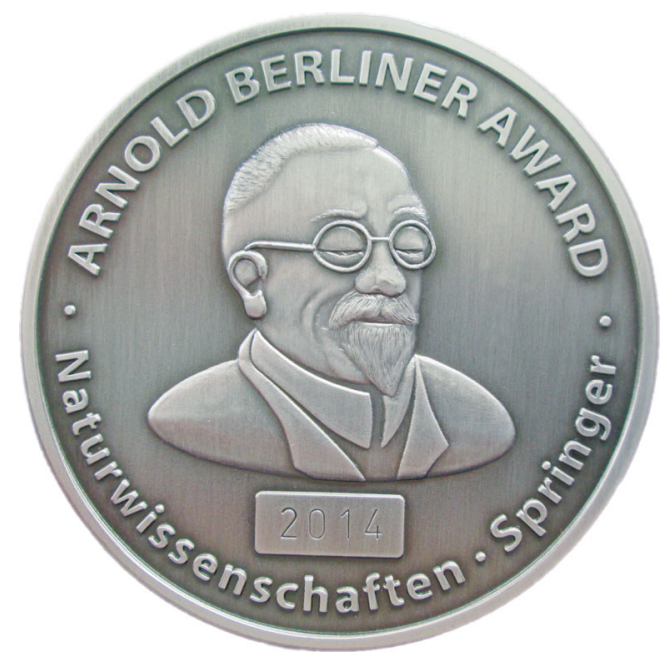

Fig. 1 The Arnold Berliner Award medal 2014. Arnold Berliner (18621942) was the founding editor of Naturwissenschaften and the journal's Editor-in-Chief from 1913-1935 (Thatje 2013a) 


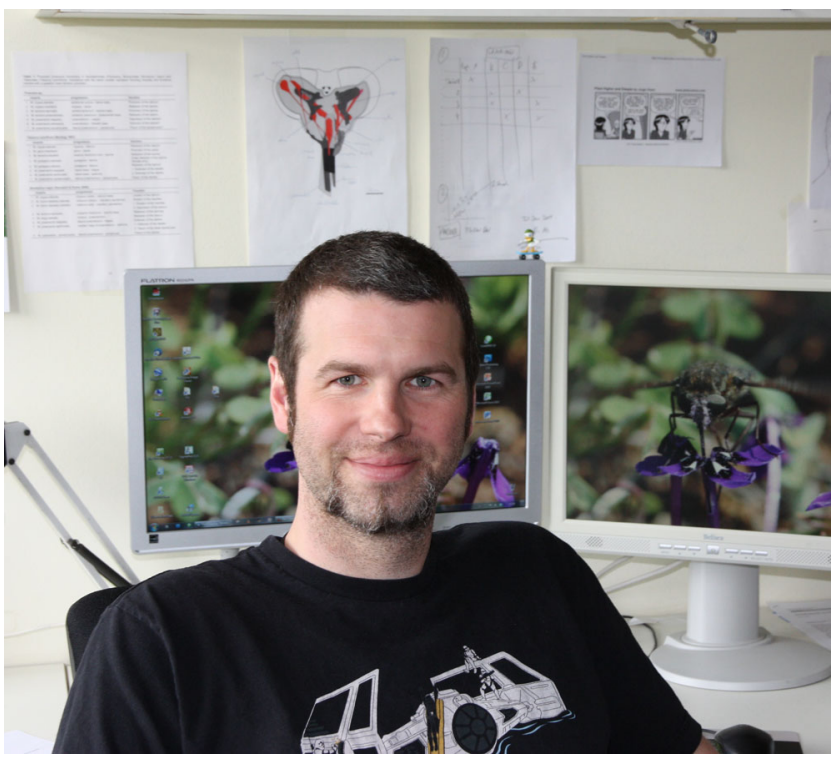

Fig. 2 Florian Karolyi, recipient of the Arnold Berliner Award 2014

functional adaptations required for long-proboscid nectar feeding and as such presents a significant advance to our understanding of the evolution of flower feeding.

The Arnold Berliner Award was established in recognition of the founding editor of the journal (Thatje 2012). As a physicist, and as an editor over the exceptionally long period of 22 years, Berliner's activities were influential and at the heart of academic life and society of his time (for biographic notes, see Thatje 2013a; O’Neil 2014). The Arnold Berliner
Award is sponsored by the Springer Science + Business Media and is given annually for the best research article published in NAWI during the previous calendar year and is given to the principal author of the respective article (Thatje 2012). Criteria are excellence in science, originality, and in particular interdisciplinarity, overall mirroring Berliner's motivation for initiating NAWI. A jury, consisting of the board of editors and the editor-inchief, selects the awardee. The award is marked with the Arnold Berliner medal (Fig. 1) and is accompanied by a biennial subscription to the electronic edition of Naturwissenschaften, a 500-euro voucher for Springer books, and a cash prize of 250 euros.

\section{References}

Karolyi F, Morawetz L, Colville JF, Handschuh S, Metscher BD, Krenn HW (2012) Time management and nectar flow: flower handling and suction feeding in long-proboscid flies (Nemestrinidae: Prosoeca). Naturwissenschaften 100:1083-1093

O'Neil R (2014) The Mahler family in the rise and fall of the Third Reich. Diadem Books ISBN 978-1-909874-45-9 (in press)

Thatje S (2012) Introducing the Arnold Berliner Award. Naturwissenschaften 99(9):675-676

Thatje S (2013a) Celebrating 100 years: happy birthday, Naturwissenschaften! Naturwissenschaften 100:1

Thatje S (2013b) Dr Arnold Berliner (1862-1942), physicist and founding editor of Naturwissenschaften. Naturwissenschaften 100: $1105-1107$ 